\title{
Septal Ablation in Obstructive Hypertrophic Cardiomyopathy (oHCM)
}

\author{
Dirceu Rodrigues Almeida \\ Universidade Federal de São Paulo (UNIFESP), São Paulo, SP - Brazil \\ Short Editorial related to the article: Retrospective Analysis of Risk Factors for Related Complications of Chemical Ablation on Hypertrophic \\ Obstructive Cardiomyopathy
}

Hypertrophic cardiomyopathy $(\mathrm{HCM})$ is the most common genetic heart disease, with a prevalence of 1 case in 500 individuals. ${ }^{1}$ The disease is very heterogeneous regarding its phenotype, being the main cause of sudden death in athletes who they die in competitions. ${ }^{1,2}$ Fortunately, most patients are asymptomatic or have few symptoms and will have a life expectancy very close to the individuals without the disease. ${ }^{2}$ However, some patients will develop symptoms such as angina, dyspnea, palpitations, syncope and even sudden death, usually caused by ventricular arrhythmia. Approximately $2 / 3$ of patients with $\mathrm{HCM}$ have a significant left ventricular outflow tract (LVOT) gradient at rest or during drug or physical exertion provocation tests. ${ }^{3}$ The presence of a significant gradient, mainly at rest, characterizes obstructive hypertrophic cardiomyopathy (OHCM) and the presence of the gradient is related to greater symptom intensity and a higher risk of death. ${ }^{1-3}$

The standard treatment of symptomatic patients comprise the use of drugs such as beta-blockers and/or calcium channel blockers, which decrease the gradient and improve angina, diastolic function and increase tolerance to physical exertion. ${ }^{1-3}$ Between 5 and $10 \%$ of patients with $\mathrm{OHCM}$ are refractory to pharmacological treatment and should be considered for invasive treatment: surgical myomectomy (SM) or septal ablation (SA) (alcoholization) with the aim of reducing septal muscle mass and relieve LVOT obstruction..$^{4,5}$ Since its introduction in 1995 by Sigwart et al., ${ }^{5}$ SA has become an alternative to surgical treatment (which was considered the gold standard treatment for patients with $\mathrm{OHCM}$ and refractory to clinical treatment). After the introduction of SA, because it was found to be attractive to the patient and to the physician, a rapid and progressive increase in the number of performed procedures was observed, especially in the European countries, which quickly surpassed the number of surgeries performed annually worldwide and with results in the short and medium term that were similar to the results obtained with surgical procedures in centers of excellence, according to data from patient cohorts, registries

\section{Keywords}

Cardiomyopathy, Hypertrophic/physiopathology; Cardiomyopathy, Hypertrophic/therapy; Heart Septum/ pathology; Heart Septum/drug effects; Ethanol/administration \& dosage; Blood Pressure.

\section{Mailing Address: Dirceu Rodrigues Almeida •}

Rua Viaza, 400 apto 415. Postal Code 04633-050, Jardim Aeroporto, São Paulo, SP - Brazil

E-mail: dirceu-almeida@uol.com.br

DOI: $10.5935 / a b c .20190066$ and meta-analyses, ${ }^{6,7}$ since there are no randomized trials comparing the two forms of intervention. But despite the significant increase in the number of SA performed and after two decades of experience, some controversy remains about the choice of invasive procedure (SA or SM?). ${ }^{4,8-11}$

As it has more than 4 decades of experience, consistent results in the longer term and it is more effective in reducing the gradient (eliminates the gradient in $>90 \%$ of the cases), the European guideline recommends surgery (septal myomectomy) performed in specialized centers (mortality rate $<2.0 \%$ and rate of complications $<5 \%$ ) as the procedure of choice (degree of recommendation la and evidence level B) and SA as an alternative, with degree of recommendation Ila and evidence level $\mathbf{C}$ for selected patients, with contraindication to surgery or at high surgical risk or even in cases of myomectomy failure. ${ }^{9}$

It is worth noting that the determinant factor for having good results with both procedures is the experience of centers, which must be measured by more than 50 procedures performed per year and more than 20 procedures performed by the operator (surgeon or interventional cardiologist), seeking to attain mortality rates $<2 \%$ and complication rates $<5 \%$. ${ }^{10,11}$

In this issue, $\mathrm{Li}$ et al. $^{12}$ report the experience of a single center in China with SA for treatment of symptomatic OHCM. The author shows the results of the procedure in 224 patients, performed according to the preference of the patient and/or the attending physician, over a period of 13 years and after the 1-year follow-up, they retrospectively analyzed the risk factors for complications related to the procedure (in-hospital phase). The rate of complications related to the procedure was $36.23 \%$, including 4 deaths, 3 cardiogenic shocks, 6 episodes of ventricular fibrillation, 1 myocardial infarction, 20 advanced AV blocks and 4 permanent pacemaker implants, plus 28 minor complications. At the multivariate analysis, only arterial hypertension stood out as a strong complication predictor. The rate of severe complications reported by the author is very high when compared to those of large series, in specialized centers and with a high volume of procedures. ${ }^{4,6-8,13}$

In the study by Li et al., ${ }^{12}$ it becomes clear that one of the factors associated with high complication rates may have been the relatively low number of procedures per year, the inclusion of older patients with comorbidities, and the inclusion of 46 hypertensive patients, who usually have a sigmoid, less thick interventricular septum; moreover, the hypertrophy may be secondary to hypertension and not necessarily observed in patients with OHCM, in addition to worsening diastolic function and being accompanied by comorbidities such as diabetes, coronary disease and atrial fibrillation.

In the large series that evaluated complications, factors related to the experience of the center and the operator and also to patient selection for SA always stand out as predictors 
of low rates of complications, especially age, comorbidities, preexisting bundle branch blocks, as well as anatomical and functional factors as determinants of complications and also of the success rate of the procedure. ${ }^{13}$

When selecting the patients for invasive treatment, one must ascertain the actual refractoriness of the clinical treatment (present in $5 \%$ of the patients in our center), evaluate the presence and impact of comorbidities, perform a careful assessment of the gradient, especially the resting gradient, since we do not know the actual influence of the inotropic stimulus on the genesis of the symptoms and the risk of death. The resting gradient should be $>30 \mathrm{mmHg}$ or ideally $>50 \mathrm{mmHg}$; the basal septum thickness $>15 \mathrm{~mm}$ or ideally $>18 \mathrm{~mm}$; one should determine that the gradient is in the outflow tract and not the mid-ventricular portion (10-15\% of cases), the presence of the anterior systolic movement of the mitral leaflet, degree and mechanism of mitral regurgitation, anatomy of the papillary muscle and, mainly, the anatomy of the dominant septal artery, collateral dependence, source of collateral, risk of remote infarction, and, finally, technical factors with appropriate material, balloon test to verify whether there is a gradient reduction, amount of alcohol to be injected and procedure monitoring with contrast echocardiogram to prevent large infarctions. ${ }^{13,4,13}$

When choosing the type of invasive procedure, SM or SA, in addition to careful patient selection, one has to consider very thoroughly the fact that even symptomatic patients have an annual risk of death $<3 \%$. Thus, the availability of specialized centers and operators with experience in both procedures is mandatory, as both invasive procedures have only been shown to date to have an impact and reduce symptoms and improve quality of life, and none has shown to be capable of reducing the risk of sudden death, which is a major concern, especially in younger patients. ${ }^{8,13}$ "We must always remember that the most important thing is to "treat the patient, not just the gradient."

\section{References}

1. Maron BJ. Clinical course and management of hypertrophic cardiomyopathy. N Engl J Med. 2018;379(20):655-68.

2. Marian AJ, Braunwal E. Hypertrophic cardiomyopathy genetics, pathogenesis, clinical manifestations, diagnosis, and therapy. Circ Res. 2017;121(7):749-70.

3. Maron BJ, Ommem SR, Sensarian C. Spirito P, Maron S. Hypertrophic cardiomyopathy present and future, with translation into contemporary cardiovascular medicine. J Am Coll Cardiol. 2014;64(1):83-99.

4. Nishimura RA, Seggewiss H, Schaff HV. Hypertrophic obstructive cardiomyopathy: surgical myectomy and septal ablation. Circ Res. 2017;121(7):771-83.

5. Sigwart U. Non-surgical myocardial reduction for hypertrophic obstructive cardiomyopath. Lancet. 1995;346(8969):211-4

6. Veselka J, Faber L, Liebregts M, Cooper R, Januska J, Krejci J, et al. Outcome of alcohol septal ablation in mildly symptomatic patients with hypertrophic obstructive cardiomyopathy: a long-term follow-Up study based on the Euro-Alcohol Septal Ablation Registry. J Am Heart Assoc. 2017;6(5):1-6.

7. Osman M, Kheiri B, Osman K, Barbarawi M, Alhamoud H, Alqahtani F, et al. Alcohol septal ablation vs myectomy for symptomatic hypertrophic

obstructive cardiomyopathy: Systematic review and meta-analysis. Clin Cardiol. 2019; 42(1):190-7.

8. Vriesendorp PA, Liebregts M, Steggerda RC, Schinkel AFL. Long-Term outcomes after medical and Invasive Treatment in patients with hypertrophic cardiomyopathy. J Am Coll Cardiol Heart Fail. 2014;2(6)630-6.

9. Elliott PM, Anastasakis A, Borger MA. Guidelines on diagnosis and management of hipertrophic cardiomyopathy. Eur Heart J. 2014;35(39):2733-79.

10. Liebregts M, Faber L, Jansen MK, Vrisendorp A, Jamuska J, Krejeci J, et al. Outcomes of alcohol septal ablation in younger patients with obstructive hypertrophic cardiomyopathy. J Am Coll Cardiol. 2017;10(11):1134-43.

11. Spirito P, Rossi J, Maron BJ. Alcohol septal ablation: in which patients and why? Ann Cardiothorac Surg. 2017;6(4):369-75.

12. Li CY, Shi YQ. Análise retrospectiva de fatores de risco para complicações relacionadas com ablação química na cardiomiopatia hipertrófica obstrutiva. Arq Bras Cardiol. 2019; 112(4):432-438.

13. Rigopoulos AG, Seggewiss H. Twenty years of alcohol septal ablation in hypertrophic obstructive cardiomyopathy. Curr Cardiol Rev. 2016;12(4):285-96 